\title{
QUALITY MONITORING MODEL IN EDUCATIONAL AND PUBLIC INSTITUTIONS IN THE CONDITIONS OF SUSTAINABLE DEVELOPMENT
}

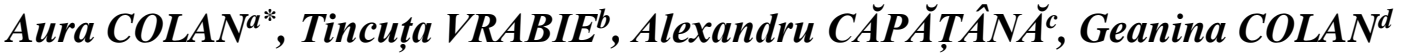 \\ a,b,c,d "Dunărea de Jos" University of Galati, Romania
}

DOI: $10.24818 / \mathrm{IMC} / 2020 / 02.19$

\begin{abstract}
The sustainable development of the educational system should take place according to the needs of the consumers of educational services by developing new modern policies and reforms, the partnership between the interested parties, the use of quality management models to the purpose of improving management efficiency. The models, methods and tools used by educational institutions create space for lifelong learning and the opportunity for flexible education. Focusing on developing sustainable systems of quality management for educational institutions shows that there is ever greater awareness of quality management in educational institutions, as they wish to increase their competitivity on the national and even European market.
\end{abstract}

KEYWORDS: decentralization, autonomy, monitoring, quality education

\section{INTRODUCTION}

The dynamics of change in the economic and social domain triggers the reformation of the support systems, including education. In order to build a high-performance educational system it is necessary to identify, on the one hand, the need for action in regard to the national educational field allowing to reach quality in education, and on the other hand, to identify the possibilities of UE support aimed at modernising the national educational systems.

It is necessary to provide coherence inside the rebuilt system, in point of both legislation, and the institutional development and functionality. The starting point should be, on the one hand, harmonising the labour market demand to the educational system supply, and on the other hand, creating a functional network between education, research and the business community in order to clearly define the knowledge, competences and abilities required by the economic and social environment. The flexibility of the educational supply should synchronise with the present demand and anticipate the medium-term educational needs.

The need for professional formation and adaptation is felt in each individual and at the level of the economic agents interested in harmonising the occupational profiles and qualification. In this respect it should be evinced that the individuals are emitters of the educational demand, and at the same time the main recipients of the information provided by the systems of professional formation and adaptation, the clients' needs have continuously changed and the need to adapt to

\footnotetext{
${ }^{*}$ Corresponding author. E-mail address: colanaura@gmail.com
} 
them seems to be the only way to allow enterprises to have a stable operation in the changing environment of the market (Nowacki, Szopiński, \& Bachnik, 2017).

Bagley, Woods and Glatter (1996) state that the market has the ability to improve education, as one of the benefits on competition increase is to impose school the strengthening of relations with all clients (students, parents, graduates, the government and the employers) and thus invites educational institutions to raise their standards in order to become more receptive to their clients' needs.

Educational institutions should start from identifying the labour force beneficiaries' needs but also take into account the training needs to the purpose of employing the trainable individual by creating a good reputation, developing educational programs, meeting the clients' needs, meeting the community needs.

Service design is obviously a beneficial method to improve the user's experience in the educational field. The SARS COVID - II 19 pandemic and the political troubles around Black Lives Matter have deeply impacted the world and the educational sector. In this new world, universities should turn a critical eye inside and re-evaluate their structures and current practices. Creating a quality culture is an essential condition for the implementation of the principles of TQM (Total Quality Management) in an educational institution. The management is responsible for creating such a culture, so that to obtain high performance in educational service quality; performance may be higher than the similar services provided by the competition. In education, the teaching/learning system should be considered the essential mission of the institution, that should be continuously improved. (Kowalik \& Klimecka-Tatar, 2018)

The decisive role played by teachers, and also by parents, administrative staff, scientific researchers in the field of education and social sciences. The results of education are seen in the future, and that is why longterm perspective is necessary, which presupposes clear identification of objectives and their communication to all the staff. The fundamental philosophy of management in education and teaching should stay the same for a long period of time, irrespective of the trends and changes occurring in the social milieu. At present it may be seen how classically furnished schools become more modern, equipped with computers. All these imply a change of methods, not of educational philosophy and objectives.

An efficient quality management system is based on a model (standard), playing the role of the reference point or the criteria system for external evaluation (the function of quality insurance) and a guide of internal organization (the quality of the management function). (Kelada,1990)

The structural models of economic organisations, based on the system's demands, criteria and descriptions allow an objective external evaluation of education. They involve a higher degree of rigour in approaching quality. The most widely known models of performance evaluation in businesses correspond to the most important awards in the world granted for quality, and organizational excellence, respectively. (Paraschivescu, 2006)

Today's Romanian school will sooner or later succeed in really passing to an organizational paradigm, to the detriment of the existing institutional one. This will trigger an extended responsibility of the managing team of the educational 'organization`. Passing to the new paradigm will compel school to take decisions based on quality management, extremely serious and anchored in the contemporary realities influenced by several highly important factors: the environment/ community where it operates, the constantly evolving labour market, the demands of the clients and also of the parties interested in the evolution of the organization in question, etc. 
These aspects lead to an (inherent) approach of quality management at the level of the school organization based on at least two fundamental elements, as previously mentioned: system and process related. Besides, the legislative framework, with an exaggerated dynamics of change, forces school to evolve more and more rationally and adequately to the resources at its disposal. This is undoubtedly necessary, much more than the strict implementation of institutionally imposed rules. It is necessary to have a quality management implemented at the level of the organization, able to operate coherently, and efficiently.

\section{EXPERIMENT}

The purpose of the case study was to develop the idea of a model of quality management in services, especially in education, but also in local public administration, based on the systemic approach, that may lead to: structuring a system whereby the organizational objectives may be reached in a real and efficient manner; understanding the interdependencies between the processes in the organization; the structured approach of process harmonization and integration; better grasp of the roles and responsibilities needed to reach the common objectives and reducing dysfunctions; understanding the ability of the organization and setting the priorities according to material constraints; defining the manner of operation for the specific activities in the system; pursuing the continual improvement of the system by measurement and assessment.

The key points of the system of an organization are those point where the relevant factors for quality may be evinced. Any public institution draws up its own quality management system, based on national regulations, the objectives set, and its experience. For instance, in universities, QMSs are supposed to contribute to the continuous improvement of the education and research process in these institutions, as well as the related services provided by universities.

\section{RESULTS AND DISCUSSIONS}

The first part of the study includes the approach of the process in quoted literature, and then the results of the questionnaire addressed to students, graduates, teaching staffbeneficiaries/citizens. The fundamental elements at the basis of any such system are:

- the expectations of students, employers and other interested parties;

- creating a proper environment for performance on all dimensions of activity;

- approaching the issue of quality from a strategic perspective: mission, values, principles, policies, strategies, objectives, etc.

- control and permanent improvement of the institutional processes;

- involving the personnel and increasing their responsibility;

- setting relevant quality indicators and evaluating them internally;

- documenting the system in view of providing objective evidence to build trust.

The questionnaire was conducted electronically, the target group consisted of 50 university graduates, 100 students and 20 teachers. The process-based definition of service quality distinguishes three main stages of the process: input, process, and output. In regard to the service and its quality, these stages may be perceived as follows: input quality, including technical quality (facilities, infrastructure and characteristics of the teaching stuff, such as knowledge, experience and training), and organizational conditions (timetable, teachers' attitude, atmosphere, etc.). 
The structure of the quiz respondents according to the study programme and the status a year after graduation (figure 1):
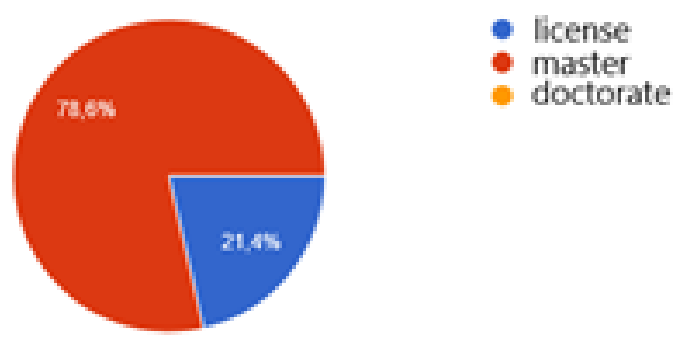

Figure 1 . The structure of the quiz respondents according

It is our opinion that the rural-urban distribution (figure 2) reflects the real situation, the study evincing the issues of both demographic categories.

Table 1 - Background

\begin{tabular}{|l|l|l|}
\hline BACKGROUND & FREQUENCY & PERCENT \\
\hline URBAN & 41 & 48.8 \\
\hline RURAL & 43 & 51.2 \\
\hline TOTAL & 84 & 100 \\
\hline
\end{tabular}

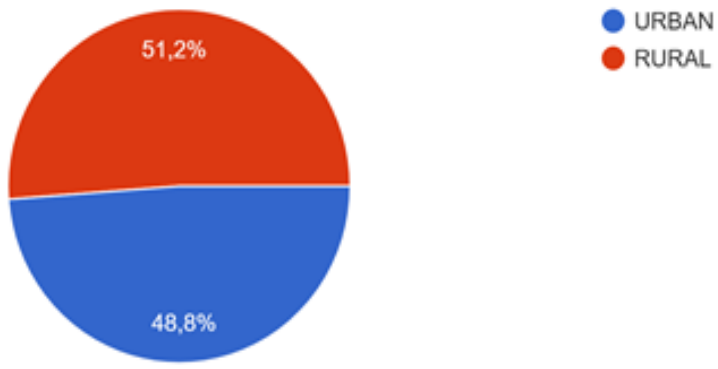

Figure 2. The rural-urban distribution

It is worth mentioning the large section of young people in the target group, over $90 \%$ of the students are up to 25 years of age, $50 \%$ of the teachers are up to 40 years of age, and the graduates are up to 25 years of age for the licence and the master's programmes, and at the same time the low number of individuals aged 55-64 (figure 3). 
Teaching staff seniority

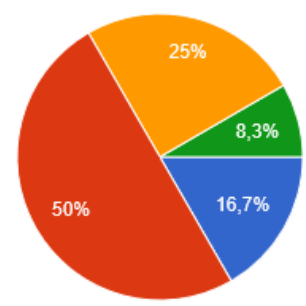

- under 10 years

10-20 years

- 20-30 years

- over 30 years

Figure 3 Teaching staff seniority

"If you are currently employed, please specify: is the position you currently hold in accordance with your training (figure 4), i.e. higher education graduate?”

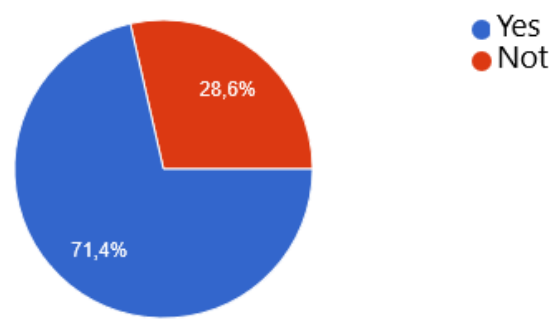

Figure 4. Position you currently hold in accordance with your training- process quality

"Which competences are required by employers when hiring a higher education graduate?”

The main requirements are the following:

1) basic knowledge according to the job description;

2) the graduate's desire to evolve in the organization;

3) seriousness and perseverance, advanced knowledge, as well as soft skills in the chosen field of activity, knowledge in Digital Marketing, etc.

The supply of professional training courses existing in the Romanian educational system (figure 5) meets the need for personal and professional development in a percentage of $42 \%$ and needs improvement for $58 \%$ of the respondents.

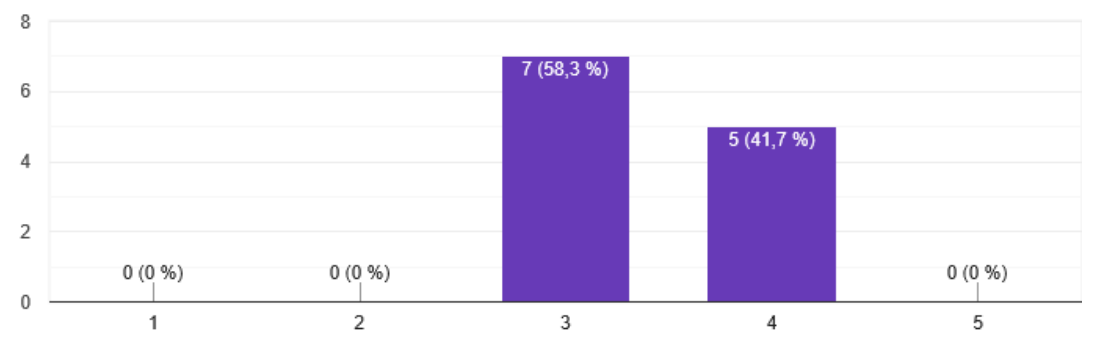

Figure 5. The supply of professional training courses existing in the Romanian educational system 
$40 \%$ of the teaching staff respondents prefer to improve the training curricula for their students, while only $10 \%$ consider that these curricula are outdated (figure 6) the initial formation programmes for teachers are
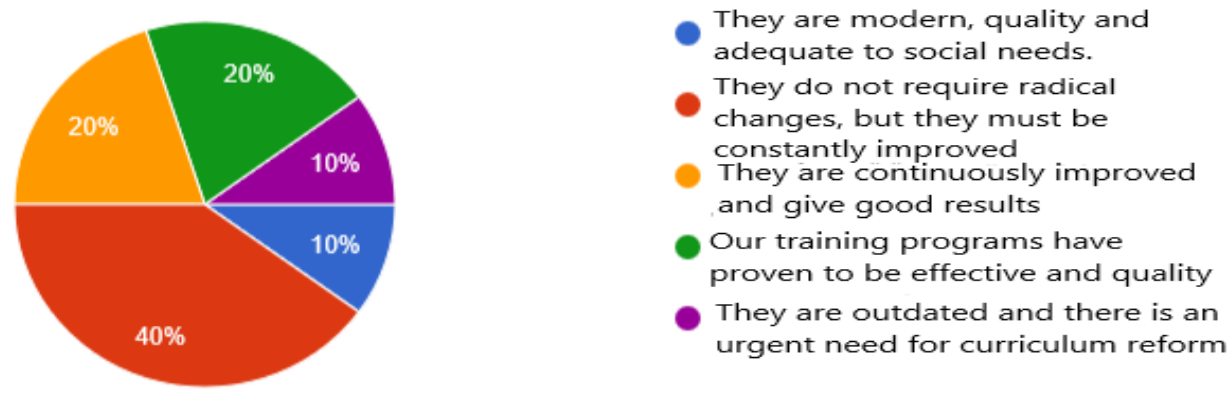

They are outdated and there is an urgent need for curriculum reform

\section{Figure 6. The initial formation programmes for teachers}

The learning competences considered as necessary for the teaching activity in the best conditions refer to digital competences, adaptation ability, career counselling for young people, entrepreneurship competences, communication skills. Methodological competences, the communication and social skills for special needs students, the ability to innovate and adapt to macroeconomic changes, adaptation and connection to the labour market, adaptation to socioeconomic changes, psycho-pedagogical skills, professional skills, intercultural skills, the foreign language (EN), scientific research, knowledge of the international databases, creative skills, discovery of new methods of conveying information, managerial skills, innovative teaching methods, that is the quality of the interaction between service supplier and receiver at the place where the service is supplied, depending mainly on aspects like time, impeccability, reliability, insurance and safety for the service provided, focusing on the employees' contact with the customer, on the basis of mutual understanding, empathy, involvement, adjustment and assistance.

- production quality, which is mainly connected to tangibles and intangibles and is in strict dependence on customer satisfaction - students, graduates.

"Are the skills acquired by the graduates during their studies (figure 7) very different from the one acquired a year after graduation on the job?”

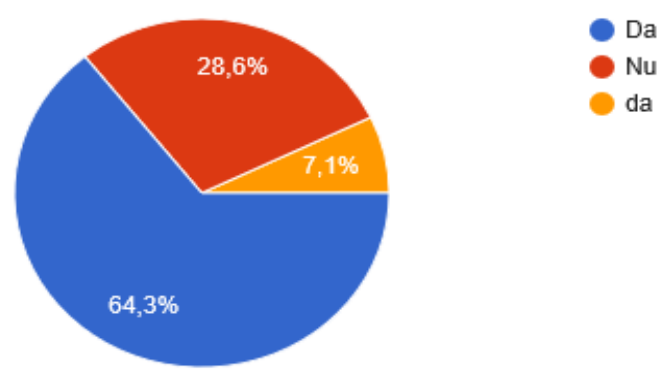

Figure 7. Skills acquired by the graduates during their studies 
The improvement directions of the formation system for the teaching staff (figure 8) refer to putting together a national skill system that is also agreed on by the employers, and the commonest means of formation proper to the professional formation objectives are a combined training form (face-to-face and online), and the most requested modality is short-time training courses and interactive seminars.
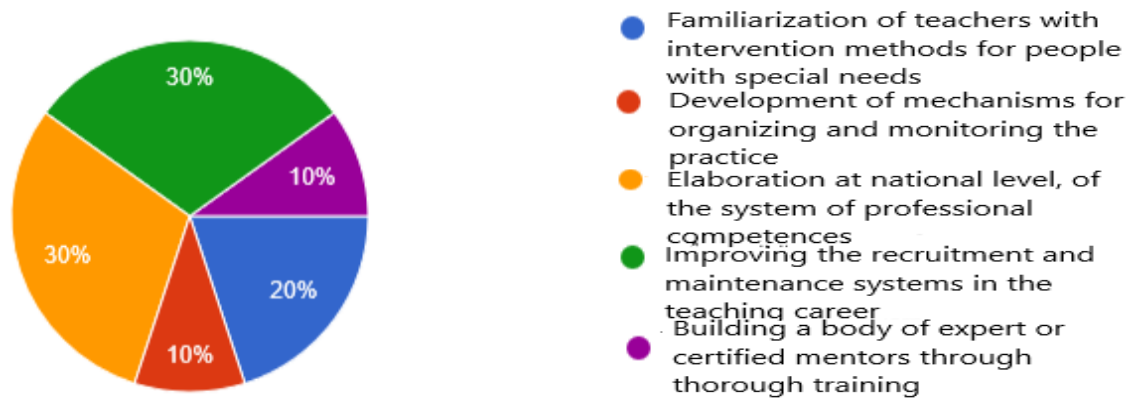

Figure 8. The improvement directions of the formation system for the teaching staff

In each category of respondents, the ones with a higher education level would participate more in completing their professional training. Thus, higher education graduates are $100 \%$ more willing to improve their training.

Taking into account that professional training for all categories that currently are or wish to be on the labour market is performed through the Romanian educational system, the authors propose a new model of the management system for educational services.

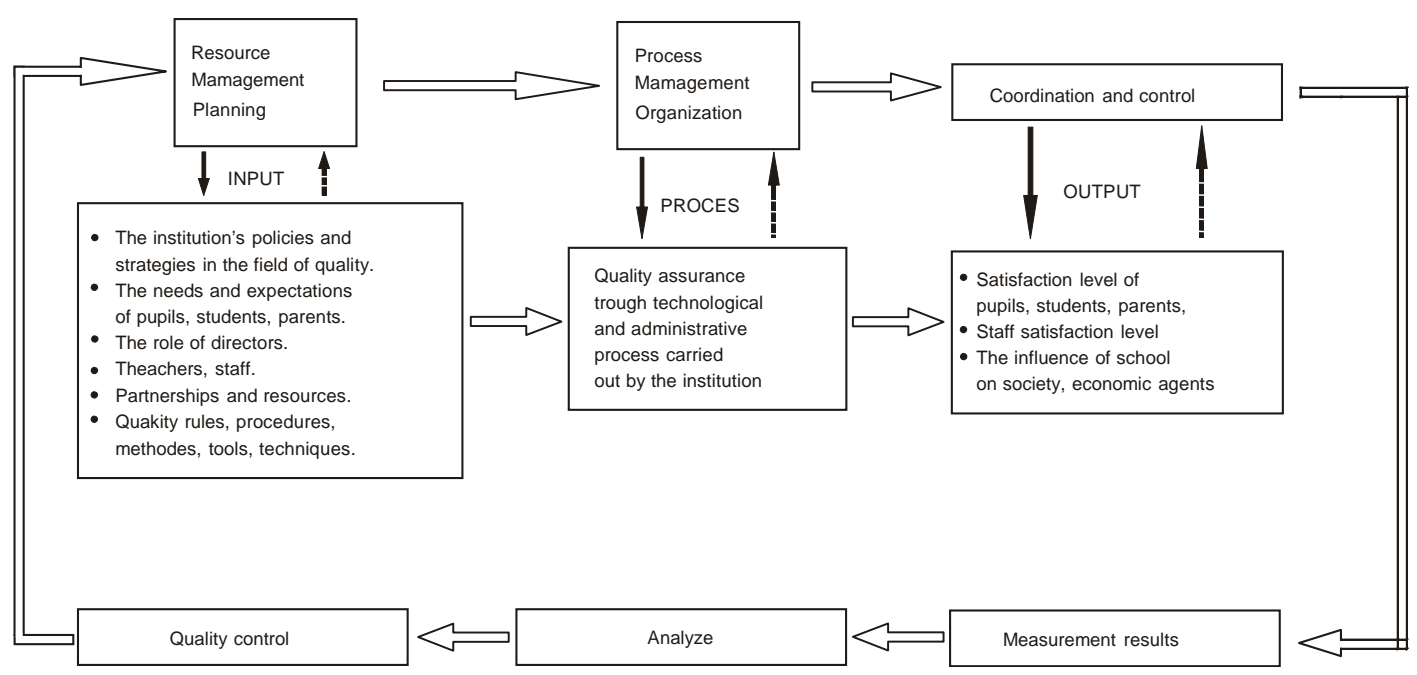

Figure 9. The authors' proposition of a new management system model of service quality

The results of the questionnaire applied to education beneficiaries confirmed the validity and complexity of service quality and the importance of its proper management. 
The results of the study of specialized literature and empirical research gave the authors an idea about a new model of management system for educational services (Figure 9).

The analysis confirmed the hypothesis - First and foremost, a unidirectional relation was found between the educational supply and the needs of the labour market. Secondly, obtaining skills is not totally determined by the expectations of the employers on the local market ,which affects the quality of the services provided. Third, the importance of individual criteria in evaluating the quality of educational services should foresee the difficulties in comparing the local tendencies with other markets, especially those that are better developed, stronger or with a longer tradition. Among the managers of the companies on the local market, there is more variation relating to the perceptions of quality-impacting criteria than among business managers who signed practical activity contracts for students with the academic institutions.

The article deals with the possibilities at the disposal of research institutions to build relations with the customers, beneficiaries, especially regarding the process of delineating the quality of the formation services. Knowing the customers' preferences in this field may help develop an adequate supply of training services and cooperate with the potential customers. The educational service, seen as a process with its input, transformation and output, is managed at every stage by the processes based on the theory of the inclusive resource management, planning, organization, control, measurement and analysis. The cycle is endless as it constantly improves as a natural consequence of the analysis of the previous action.

\section{CONCLUSION}

This level may be evaluated according to the quality of the educational services provided by specialized centres of professional training. But the ongoing restructuring of education in our country makes it impossible to lay it on a solid foundation. The educational market in the field of ongoing professional training is still in its initial stages of development, and that's why its level is not very high. Increasing competition between the organizations providing such services and hence increasing the quality of the services rendered, focusing on the customer, may be useful to both the beneficiaries (the companies), and those who want to enter the labour market.

The results provided in the paper show that quality insurance in education/ public institutions refers to the totality of policies, processes and actions by managers of the educational public institutions whereby quality is maintained and developed in education, providing information on the operation of the educational system, together with the results obtained and the possible means of improving them; taking responsibility for the creation of favourable conditions to reach quality standards; maintaining and improving high academic standards; proving the high quality of academic or professional training programs, either initial or ongoing, for all the students of a higher learning institution; developing a quality-centred institutional culture and providing real protection for the beneficiary or the student.

Quality insurance is necessary as it prevents the occurrence of problems, and more importantly, it is a global, systemic, managerial approach. This concept $\mathrm{s}$ the subject of quality management. Quality management is seen as a totality of the activities pertaining to the general management function, triggering the policy in the quality domain, its objectives and responsibilities, as well as their implementation by means like: planning, control, quality insurance and improvement, in a framework including the organization structure, the procedures, processes and resources necessary to an organization. Implementing a quality system is similar to a management project, 
and in order to reach the objectives there should be involvement and dedication on the part of both management and employees.

\section{REFERENCES}

Bagley, C., Wood, P. \& R. Glatter, (1996), Scanning the market: school strategies for discovering parental perspectives, Educational Management and Administration, 24(2), 125138.

Kowalik, K. \& Klimecka-Tatar, D. (2018). The process approach to service quality management. Production Engineering Archives 18, 31-34, doi: 10.30657/pea.2018.18.05

Nowacki, R., Szopiński, T.S. \& Bachnik, K. (2017). Determinants of assessing the quality of advertising services - The perspective of enterprises active and inactive in advertising. Journal of Business Research, 474-480. doi: 10.1016/j.jbusres.2017.12.017.

Kelada, J. (1990). La gestion integrale de la qualite. Pour une qualite totale. Quebec: Editor Quafec

Paraschivescu, A. O. (2006). Managementul Calității. Iași: Editura Tehnopress. 